\section{(6) OPEN ACCESS}

\title{
PPAR $\gamma$ deficiency results in severe, accelerated osteoarthritis associated with aberrant mTOR signalling in the articular cartilage
}

\author{
Faezeh Vasheghani, ${ }_{1}^{1}$ Yue Zhang ${ }^{2}$ Ying-Hua Li, ${ }^{2}$ Meryem Blati, ${ }^{1}$ Hassan Fahmi, \\ Bertrand Lussier, ${ }^{3}$ Peter Roughley, ${ }_{1}^{4}$ David Lagares, ${ }^{5}$ Helal Endisha, ${ }_{1}{ }^{B}$ Bahareh Saffar, ${ }^{2}$ \\ Daniel Lajeunesse, ${ }^{1}$ Wayne K Marshall, ${ }^{6}$ Y Raja Rampersaud, ${ }^{6}$ Nizar N Mahomed, ${ }^{6}$ \\ Rajiv Gandhi, ${ }^{6}$ Jean-Pierre Pelletier, ${ }^{1}$ Johanne Martel-Pelletier, ${ }^{1}$ Mohit Kapoor ${ }^{1}$, 2, 6,7
}

\begin{abstract}
Handling editor Tore K Kvien
- Additional material is published online only. To view please visit the journal online (http://dx.doi.org/10.1136/ annrheumdis-2014-205743).

For numbered affiliations see end of article.

\section{Correspondence to} Dr Mohit Kapoor, The Toronto Western Research Institute, Toronto Western Hospital, The University Health Network (UHN), 60 Leonard Avenue, Toronto, Ontario, M5T 2S8, Canada;

mkapoor@uhnresearch.ca
\end{abstract}

Received 14 April 2014 Revised 18 November 2014 Accepted 7 December 2014

Published Online First

8 January 2015

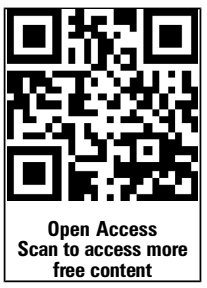

CrossMark

\section{S Linked}

http://dx.doi.org/10.1136 annrheumdis-2014-206884

To cite: Vasheghani $F$ Zhang Y, Li Y-H, et al. Ann Rheum Dis 2015;74:569578.

\section{ABSTRACT}

Objectives We have previously shown that peroxisome proliferator-activated receptor gamma (PPAR $\gamma$ ), a transcription factor, is essential for the normal growth and development of cartilage. In the present study, we created inducible cartilage-specific PPAR $\gamma$ knockout (KO) mice and subjected these mice to the destabilisation of medial meniscus (DMM) model of osteoarthritis (OA) to elucidate the specific in vivo role of PPAR $\gamma$ in OA pathophysiology. We further investigated the downstream PPAR $\gamma$ signalling pathway responsible for maintaining cartilage homeostasis.

Methods Inducible cartilage-specific PPAR $\gamma$ KO mice were generated and subjected to DMM model of OA. We also created inducible cartilage-specific PPAR $\gamma /$ mammalian target for rapamycin (mTOR) double KO mice to dissect the PPAR $\gamma$ signalling pathway in OA. Results Compared with control mice, PPAR $\gamma$ KO mice exhibit accelerated OA phenotype with increased cartilage degradation, chondrocyte apoptosis, and the overproduction of OA inflammatory/catabolic factors associated with the increased expression of mTOR and the suppression of key autophagy markers. In vitro rescue experiments using PPAR $\gamma$ expression vector reduced mTOR expression, increased expression of autophagy markers and reduced the expression of $\mathrm{OA}$ inflammatory/catabolic factors, thus reversing the phenotype of PPAR $\gamma$ KO mice chondrocytes. To dissect the in vivo role of mTOR pathway in PPAR $\gamma$ signalling, we created and subjected PPAR $\gamma$-mTOR double KO mice to the OA model to see if the genetic deletion of mTOR in PPAR $\gamma$ KO mice (double KO) can rescue the accelerated OA phenotype observed in PPAR $\gamma$ KO mice. Indeed, PPAR $\gamma$-mTOR double KO mice exhibit significant protection/reversal from OA phenotype.

Significance PPAR $\gamma$ maintains articular cartilage homeostasis, in part, by regulating mTOR pathway.

\section{INTRODUCTION}

Osteoarthritis (OA) is among the most prevalent chronic human health disorders, and the most common form of arthritis. Typical characteristics of OA include cartilage deterioration/damage, inflammation, synovial fibrosis, subchondral bone remodelling and osteophyte formation. ${ }^{1-4}$ Chondrocytes are essential for maintaining homeostasis as well as integrity of the extracellular matrix (ECM) within the articular cartilage. We are now beginning to understand the mechanisms leading to altered cartilage homeostasis, accelerated chondrocyte cell death and subsequent cartilage degeneration during OA. We and others have recently reported that the process of autophagy, a form of programmed cell survival, ${ }^{5}$ is dysregulated during OA and may contribute to the decreased chondroprotection and degradation of the articular cartilage. ${ }^{6-10}$ Carames et $a l .{ }^{9}$ showed that autophagy is a protective mechanism in normal cartilage, and its aging-related loss is associated with cell death and OA. We have also shown that during OA, excessive mammalian target for rapamycin (mTOR) (major negative regulator of autophagy) signalling and the subsequent suppression of autophagy may contribute to cartilage degradation. ${ }^{6}$ The genetic deficiency of mTOR and treatment with rapamycin (mTOR inhibitor) has been shown to reduce the severity of experimental OA. $^{6} 10$ However, endogenous mediators that control mTOR signalling and ultimately chondrocyte cell death/survival mechanisms in the articular cartilage are unknown. Identifying such endogenous factors that control mTOR signalling and articular cartilage homeostasis could lead to several promising therapeutic strategies in OA.

PPAR $\gamma$ is a ligand-activated transcription factor originally identified to play a key role in lipid homeostasis. We and others have shown that PPAR $\gamma$ possesses potent anti-inflammatory, anticatabolic and antifibrotic properties, and is a potential therapeutic target for OA disease. ${ }^{11-18}$ Since global PPAR $\gamma$ knockout (KO) mice are not viable, ${ }^{19}$ and cartilage-specific PPAR $\gamma$ germ-line KO mice exhibit serious growth and developmental defects, ${ }^{13}{ }^{14}$ we created inducible PPAR $\gamma$ $\mathrm{KO}$ mice using Col2-rTACre-doxycycline system to bypass the early developmental defects and to specifically elucidate the in vivo role of PPAR $\gamma$ in OA pathophysiology. This study first explored the role of PPAR $\gamma$ in chondro-protection by determining the effect of PPAR $\gamma$ deletion on mTOR and autophagy signalling pathway and its subsequent effect on the kinetics of OA progression and severity using mice models of OA. In addition to cartilage-specific PPAR $\gamma$ $\mathrm{KO}$ mice, we also generated inducible cartilagespecific PPAR $\gamma$-mTOR double KO mice to specifically dissect the in vivo role of mTOR pathway in PPAR $\gamma$ signalling during OA. This study is the first to show 
that PPAR $\gamma$ is involved in maintaining articular cartilage homeostasis, in part, through the modulation of mTOR signalling pathway.

\section{METHODS}

\section{Generation of inducible cartilage-specific PPAR $\gamma$ KO mice}

Inducible cartilage-specific PPAR $\gamma \mathrm{KO}$ mice were generated by mating mice containing a PPAR $\gamma$ gene flanked by LoxP sites (C57BL/6-PPAR $\gamma f l / f l$, Jackson Laboratory) with C57BL/6 Col2-rt-TA-Cre transgenic mice ${ }^{20}$ (obtained from Dr Peter Roughley, McGill University, Montreal, Canada) as we have previously reported. ${ }^{6}$ Six-week old PPAR $\gamma^{\text {fl/fl }}$ Cre mice were fed doxycycline (Sigma) dissolved at $10 \mu \mathrm{g} / \mathrm{mL}$ in phosphate buffered saline (PBS), $\mathrm{pH} 7.4$, by oral gavage with the dose of $80 \mu \mathrm{L} / \mathrm{g}$ body weight for 7 days. rtTA requires interaction with doxycycline (Sigma-Aldrich, Oakville, Ontario, Canada) to permit interaction with the TetO sequence to drive Cre expression resulting in the inactivation of PPAR $\gamma$ floxed alleles to generate a cartilage-specific PPAR $\gamma \mathrm{KO}$ mice. PPAR $\gamma^{\mathrm{fl} / \mathrm{fl}}$ Cre mice without doxycycline (saline) treatment were used as control mice. The routine genotyping of ear punch DNA followed by the confirmation of loss of PPAR $\gamma$ expression in chondrocytes by reverse transcription PCR (RT-PCR), western blotting and immunohistochemistry was performed. All animal procedures and protocols were approved by the Comité Institutionnel de protection des animaux (Institutional Animal Protection Committee) of the University of Montreal Hospital Research Centre (CRCHUM).

\section{Surgically induced $O A$ mouse model}

Control mice and PPAR $\gamma \mathrm{KO}$ mice were subjected to surgically induced OA by the destabilisation of the medial meniscus (DMM model) in the right knee of 10 -week-old animals as we have previously described. ${ }^{62}$ Briefly, after anaesthesia with isoflurance in $\mathrm{O}_{2}$, the cranial attachment of the medial meniscus to the tibial plateau (menisco-tibial ligament) of the right knee was transected. A sham operation, consisting of an arthrotomy without the transaction of the cranial menisco-tibial ligament, was also performed in the right knee joint of separate control and PPAR $\gamma \mathrm{KO}$ mice.

\section{Histology}

Freshly dissected mouse knee joints were fixed overnight in TissuFix (Chaptec, Montreal, Quebec, Canada), decalcified for $1.5 \mathrm{~h}$ in RDO Rapid Decalcifier (Apex Engineering, Plainfield, Illinois, USA), further fixed in TissuFix overnight, followed by embedding in paraffin and sectioning. Sections $(5 \mu \mathrm{m})$ were deparaffinised in xylene followed by a graded series of alcohol washes. Sections were stained with Safranin-O/Fast Green (Sigma-Aldrich, Oakville, Ontario, Canada) according to the manufacturer's recommendations. Slides were evaluated by two independent readers in a blinded fashion. To determine the extent of cartilage degeneration, histological scoring method issued by Osteoarthritis Research Society International (OARSI) was used for analysis as previously described. ${ }^{6} 22$

\section{Immunohistochemistry and TUNEL staining}

Immunohistochemistry (IHC) studies were performed using specific antibodies for target genes. For IHC analysis, Dakocytomation (Dako)-labelled streptavidin biotin +System horseradish peroxidase kit was used following the manufacturer's recommended protocol as previously described. ${ }^{14}$ Five micrometer sections were deparaffinised in xylene followed by a graded series of alcohol washes. Endogenous peroxide was blocked for $5 \mathrm{~min}$ using 3\% $\mathrm{H}_{2} \mathrm{O}_{2}$. Non-specific IgG binding was blocked by incubating sections with bovine serum albumin (BSA) (0.1\%) in PBS for $1 \mathrm{~h}$. Sections were then incubated with primary antibody in a humidified chamber and left overnight at $4^{\circ} \mathrm{C}$. Next, sections were incubated with biotinylated link for $30 \mathrm{~min}$ followed by streptavidin for $1 \mathrm{~h}$. The diaminobenzidine tetrahydrochloride chromogen substrate solution was then added until sufficient colour developed. Terminal deoxynucleotidyl transferase (TdT) dUTP Nick-End Labeling (TUNEL) assay was performed using ApopTag Plus Peroxidase In Situ Apoptosis Detection Kit according to the manufacturer's recommendations (Millipore, Ontario, Canada). The quantification of number of positive cells for each antigen was performed by the determination of the total number of chondrocytes and the total number that stained positive for the antigen. The final results were expressed as the percentage of positive cells for the antigen.

\section{Chondrocyte primary cell culture}

The microdissection of mouse knee articular cartilage (medial and lateral femoral condyle and tibial plateau) was performed under a surgical microscope (Motic SMZ-168; Fisher Scientific Canada, Ottawa, Ontario, Canada) to carefully dissect only articular cartilage and avoid subchondral bone. Primary chondrocytes were prepared from the dissected articular cartilage by enzymatic digestion as previously described. ${ }^{6}{ }^{13}$ Briefly, dissected articular cartilage was rinsed in PBS, and incubated at $37^{\circ} \mathrm{C}$ for $15 \mathrm{~min}$ in trypsin-ethylenediaminetetraacetic acid followed by digestion with $2 \mathrm{mg} / \mathrm{mL}$ collagenase at $37^{\circ} \mathrm{C}$ for $2 \mathrm{~h}$ in Dulbecco's modified Eagle's medium (DMEM) containing 10\% fetal bovine serum (FBS), $100 \mathrm{U} / \mathrm{mL}$ penicillin, and $100 \mu \mathrm{g} / \mathrm{mL}$ streptomycin under an atmosphere of $5 \% \mathrm{CO}_{2}$. The cell suspension was filtered through a $70-\mu \mathrm{m}$ cell strainer (Falcon, Fort Worth, Texas, USA), washed, counted and plated with DMEM containing $10 \% \mathrm{FBS}, 100 \mathrm{U} / \mathrm{mL}$ penicillin, and $100 \mu \mathrm{g} / \mathrm{mL}$ streptomycin under an atmosphere of $5 \% \mathrm{CO}_{2}$. At confluence, the cells were detached and plated at a density of $2 \times 10^{5}$ cells/ well in six-well plates for experiments. Only first-passage cells were used for the experiments.

\section{Transfection}

Transient transfection experiments were performed using the Transfectine TMLipid Reagent according to the manufacturer's recommended protocol (Biorad, Mississauga, Canada). Briefly, chondrocytes were seeded $24 \mathrm{~h}$ prior to transfection at a density of $2 \times 10^{5}$ cells/well in six-well plates, and transiently transfected with $1 \mu \mathrm{g}$ of the PPAR $\gamma$ expression vector, or control plasmid (pcDNA empty vector) in the presence of transfectin. After $5 \mathrm{~h}$, the medium was changed with DMEM containing 1\% fetal calf serum, and samples were incubated at $37^{\circ} \mathrm{C}$ in an incubator containing 5\% $\mathrm{CO}_{2}$ for $48 \mathrm{~h}$. PPAR $\gamma$ expression and pcDNA empty vectors were donated by Dr R Evans (The Salk Institute, San Diego, California, USA). Cells were then harvested for RNA and protein extractions as previously described. ${ }^{13}$

\section{RNA isolation and real-time PCR}

Primary chondrocytes were prepared from the dissected articular cartilage and cultured as discussed above. Total RNA was isolated from the chondrocytes using Trizol (Invitrogen, Burlington, Ontario, Canada). RNeasy Mini kit (QIAGEN, Toronto, Ontario, Canada) was used, including on-column DNase digestion to eliminate DNA (RNase-Free DNase Set, QIAGEN). RNA were reverse transcribed and amplified using the QuantiTect Reverse Transcription PCR Kit (QIAGEN) on the Rotor Gene 3000 realtime PCR system (Corbett Research, Mortlake, Australia) according to the manufacturer's protocol as shown before. ${ }^{6}$ Fold increase in PCR products was analysed using a $2^{-\Delta \Delta \mathrm{Ct}}$ method. All experiments were performed in duplicate for each sample, and the primers were designed using Primer3 online software. Data were normalised to 
glyceraldehyde 3-phosphate dehydrogenase (GAPDH) messenger RNA (mRNA) levels and represent averages and SEM. The statistical significance of quantitative polymerase chain reaction (qPCR) results was determined by a two-way analysis of variance with the Bonferroni post-test, using GraphPad Prism V.3.00 for Windows.

\section{Western blotting}

Cells were lysed in Tris-buffered saline containing $0.1 \%$ sodium dodecyl sulphate (SDS), and the protein content of the lysates was determined using bicinchoninic acid protein assay reagent (Pierce Rockford) with BSA as the standard. Cell lysates were adjusted to identical equals of protein and then were applied to SDS-polyacrylamide gels $(10 \%-15 \%)$ for electrophoresis. Next, the proteins were electroblotted onto polyvinylidene fluoride membranes. After the membranes were blocked in $10 \mathrm{mM}$ Tris-buffered saline containing $0.1 \%$ Tween- 20 (TBS-T) and 5\% skimmed milk, the membranes were probed for $1.5 \mathrm{~h}$ with the respective antibodies in TBS-T. After washing the membranes with TBS-T, the membranes were incubated overnight with horseradish peroxidaseconjugated antirabbit, or horseradish peroxidase-conjugated antimouse IgG (1:10 000 dilution in TBS-T containing 5\% skimmed milk) at $4^{\circ} \mathrm{C}$. Subsequently, by further washing with TBS-T, protein bands were visualised with an enhanced chemiluminescence system using a Bio-Rad Chemidoc Apparatus.

\section{Generation of inducible cartilage-specific PPAR $\gamma$-mTOR double KO mice}

The generation of inducible cartilage-specific PPAR $\gamma$-mTOR double $\mathrm{KO}$ mice was performed by using the Cre-Lox methodology. First, $\mathrm{mTOR}^{\mathrm{f} / \mathrm{f}} \mathrm{Col} 2$-rt-TA-Cre mice were generated by mating mice containing an mTOR gene flanked by LoxP sites (C57BL/6-mTOR ${ }^{\mathrm{f} / / \mathrm{l}}$, Jackson Laboratory) with C57BL/6 Col2-rt-TA-Cre transgenic mice as previously reported. ${ }^{6}$ Subsequently, PPAR $\gamma^{\mathrm{t} / \mathrm{f}} \mathrm{Col} 2$-rt-TA-Cre mice were crossed with $\mathrm{mTOR}^{\mathrm{fl} / \mathrm{f}} \mathrm{Col} 2$-rt-TA-Cre to create PPAR $\gamma^{\mathrm{fl} /}$ ${ }^{\mathrm{fl}}$-mTOR ${ }^{\mathrm{f} / \mathrm{fl}} \mathrm{Col} 2$-rtTA-Cre animals. Next, 6-week-old PPAR $\gamma^{\mathrm{A} / \mathrm{f}}-\mathrm{mTOR}^{\mathrm{f} / \mathrm{fl}} \mathrm{Col} 2$-rtTA-Cre mice were fed doxycycline (sigma-) dissolved at $10 \mu \mathrm{g} / \mathrm{mL}$ in PBS by oral gavage with the dose of $80 \mu \mathrm{L} / \mathrm{g}$ body weight for 7 days. The routine genotyping of ear punch DNA followed by the confirmation of loss of PPAR $\gamma$ and mTOR expression in the chondrocytes by RT-PCR, and western blotting was performed. ${ }^{61320}$ All animal procedures were approved by the Comité Institutionnel de protection des animaux (Institutional Animal Protection Committee) of the University of Montreal Hospital Research Centre (CRCHUM). PPAR $\gamma \mathrm{fl} /$ fl-mTORfl/fl-Col2-rtTA-Cre treated with doxycycline are refereed as PPAR $\gamma$-mTOR double KO mice, whereas PPAR $\gamma \mathrm{fl} / \mathrm{fl}-\mathrm{mTORfl} /$ flCol2-rtTA-Cre treated with saline (control) are referred as control mice. Mice, 10 weeks old, were subjected to DMM OA surgery and were sacrificed at 10 weeks postsurgery for histo-morphometric evaluation and biochemical analyses.

\section{Statistical analysis}

Statistical analysis, unless stated otherwise, was performed using the two-tailed Student's $\mathrm{t}$ test; $\mathrm{p}<0.05$ was considered statistically significant.

\section{RESULTS}

\section{PPAR $\gamma$ KO mice exhibit accelerated OA phenotype}

To determine the specific in vivo role of PPAR $\gamma$ in OA pathophysiology, we first generated inducible cartilage-specific PPAR $\gamma \mathrm{KO}$ mice. The presence of Cre transgene in PPAR $\gamma^{\mathrm{A} / \mathrm{fl}}$ mice was confirmed by genotyping (figure 1A). PPAR $\gamma^{\mathrm{A} / \mathrm{fl}}$ Cre mice that were 6 weeks old were fed doxycycline (or saline for controls) for 1 week by oral gavage, and the loss of PPAR $\gamma$ expression in articular chondrocytes was confirmed by qPCR, western blotting and immunohistochemistry in 10-week-old mice (figure 1B-D).

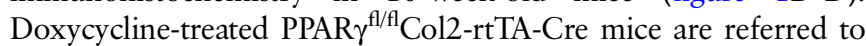
as PPAR $\gamma \mathrm{KO}$ mice, and saline-treated PPAR $\gamma^{\mathrm{f} / \mathrm{f} / \mathrm{Col} 2 \text {-rtTA-Cre }}$ mice are referred as control mice throughout the manuscript. The assessment of weight, size, as well as histological analysis of articular cartilage at 10 weeks and 6 months (see online supplementary figure S1) postbirth, showed no significant phenotypic differences between control and inducible cartilage-specific PPAR $\gamma \mathrm{KO}$ mice. We then subjected 10-week-old male control and PPAR $\gamma \mathrm{KO}$ mice to a DMM model of OA, or sham surgery, and determined the kinetics of OA at 5 and 10 weeks post-OA surgery. As expected, histological analysis at 5 weeks post-OA surgery, control mice knee joints showed some loss of proteoglycans (loss of safranin O staining), roughening of the articular cartilage, and some loss of articular chondrocyte cellularity (figure 1E). However, PPAR $\gamma \mathrm{KO}$ mice showed greater loss of proteoglycans, the loss of cellularity and destruction in some regions of the articular cartilage at 5 weeks post-OA surgery. This phenotype became more profound at 10 weeks post-OA surgery, where PPAR $\gamma \mathrm{KO}$ mice, in comparison with control mice, showed significant and severe destruction of the articular cartilage (in both medial tibial plateau and medial femoral condyle) associated with greater loss of proteoglycans and chondrocyte cellularity. These results were confirmed by the significant increase in the OARSI scores (figure $1 \mathrm{~F}$ ) and significant loss of articular chondrocytes (figure 1G) in PPAR $\gamma$ KO mice compared with control mice post-OA surgery (figure $1 \mathrm{~F}$ ).

\section{PPAR $\gamma$ KO mice exhibit enhanced cell death, increased expression of catabolic/inflammatory markers, and decreased expression of anabolic markers}

Since we observed decreased articular chondrocyte cellularity in PPAR $\gamma$ KO OA mice compared with control OA mice, we isolated chondrocytes from PPAR $\gamma \mathrm{KO}$ and control mice at 5 weeks post-OA surgery, and determined the expression of poly (ADP-ribose) polymerase (PARP) p85 by western blotting to account for cell apoptosis. Results showed increased expression of PARPp85 in PPAR $\gamma$ KO OA chondrocytes compared with control OA chondrocytes (figure 2A, B). TUNEL assay further confirmed enhanced cell death (increased percentage of TUNEL-positive cells) in PPAR $\gamma \mathrm{KO}$ mice compared with control mice at 10 weeks post-OA surgery (figure 2C, D).

Since matrix metalloproteinases (MMP)-13 is one of the major catabolic factors implicated in OA, we determined the expression of MMP-13 by IHC. Our results showed an increase in the percentage of MMP-13-positive cells in PPAR $\gamma$ KO mice compared with control mice at 10 weeks post-OA surgery (figure $2 \mathrm{E}, \mathrm{F}$ ). Further, qPCR analysis on isolated chondrocytes from PPAR $\gamma$ KO OA mice and control OA mice showed the enhanced gene expression of MMP-13, ADAMTS-5 (another key catabolic factor implicated in $\mathrm{OA}$ ), enhanced expression of inflammatory-inducible enzymes including cyclooxygenase-2 (COX-2) and inducible nitric oxide synthase (iNOS), and the decreased expression of collagen type II and aggrecan (two major anabolic components of the ECM of the articular cartilage) in PPAR $\gamma$ KO mice OA chondrocytes compared with control OA mice chondrocytes (figure $2 \mathrm{G}$ ). These results show that PPAR $\gamma$ KO mice subjected to OA surgery exhibit accelerated chondrocyte loss and enhanced catabolic activity in the articular cartilage.

\section{PPAR $\gamma$ deficiency results in aberrant mTOR and autophagy signalling}

We have previously shown that during OA, excessive mTOR (major negative regulator of autophagy) signalling and the 

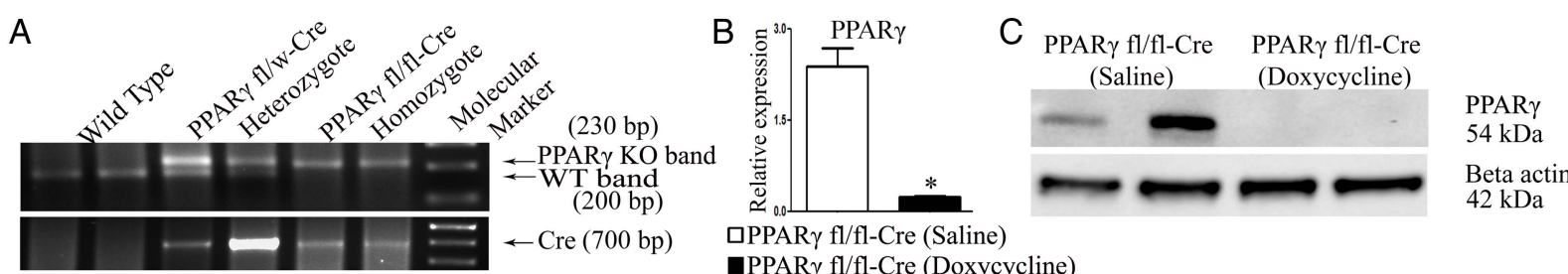

口PPAR $\gamma \mathrm{fl} / \mathrm{fl}-\mathrm{Cre}$ (Saline)

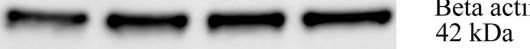

-PPAR $\gamma$ fl/fl-Cre (Doxycycline)

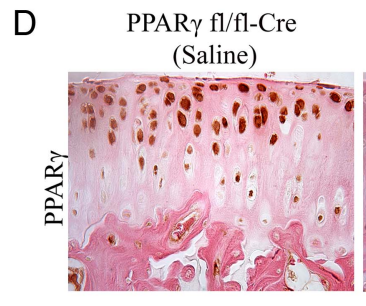

PPAR $\gamma$ fl/fl-Cre

(Doxycycline)

E
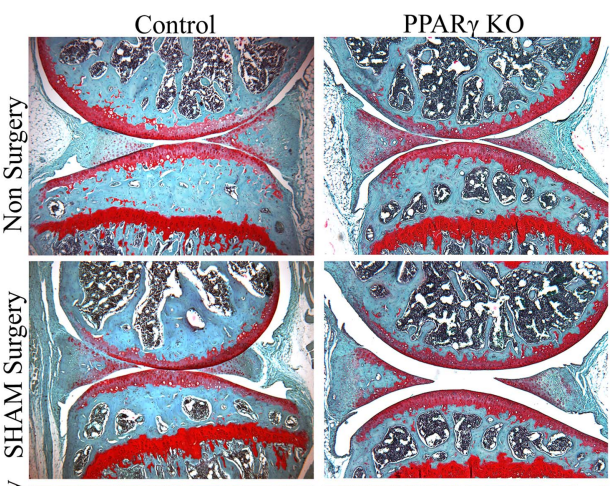

F

$\square$ Control

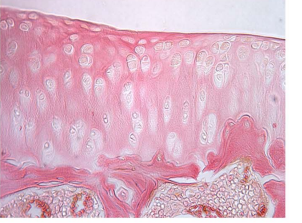

- PPAR $\gamma \mathrm{KO}$
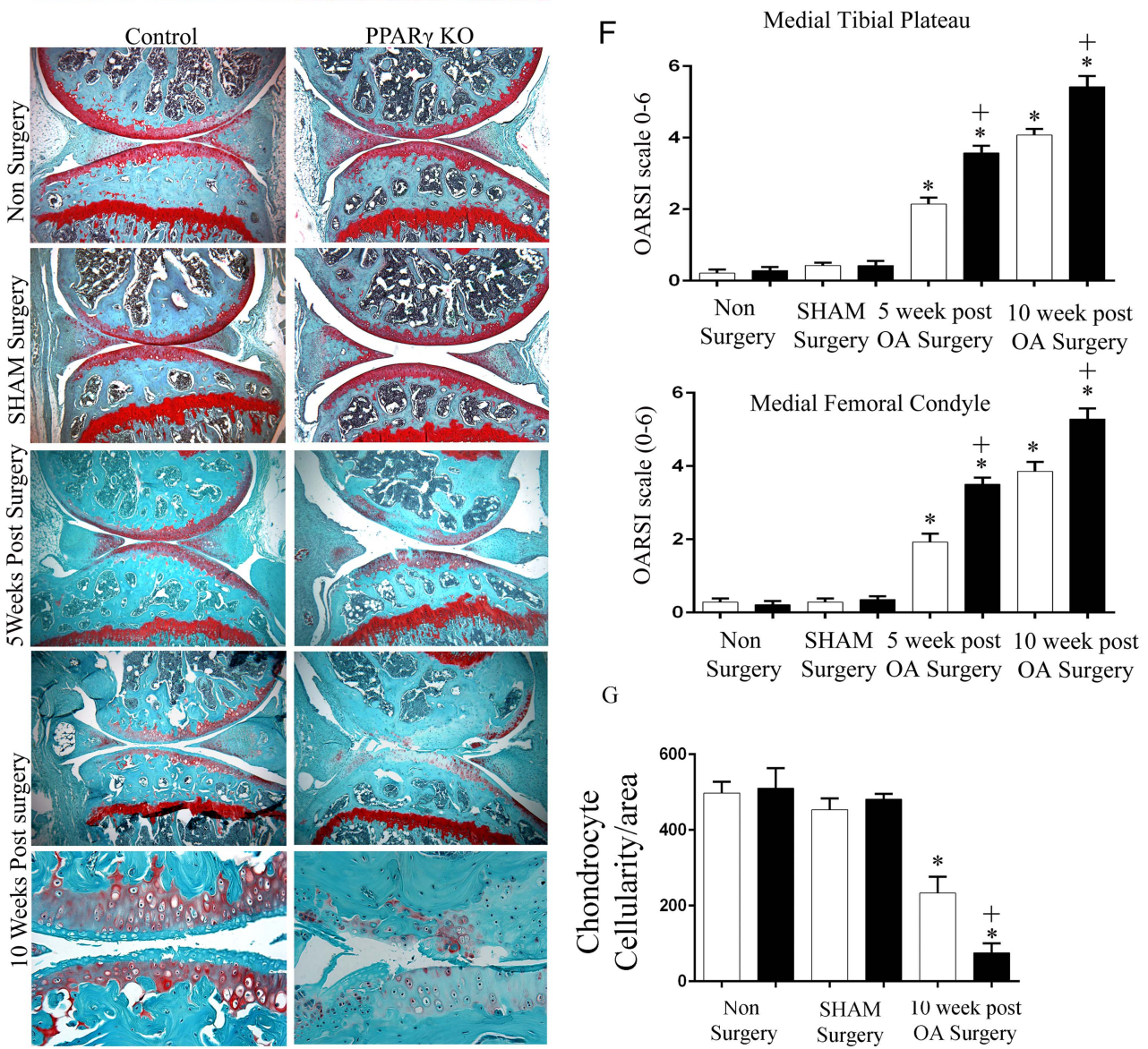

G

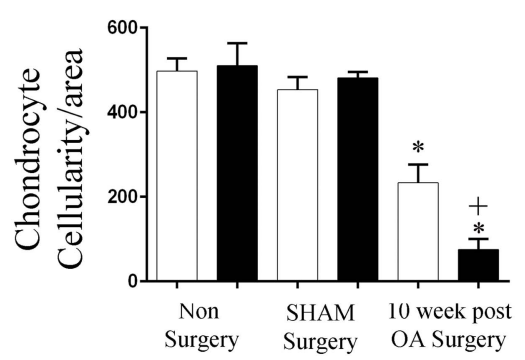

Figure 1 Peroxisome proliferator-activated receptor gamma (PPAR $\gamma$ ) knockout (KO) mice exhibit accelerated osteoarthritis (OA) phenotype: (A) genotyping confirmed the presence of the Cre transgene in heterozygote (PPAR $\gamma^{\mathrm{fl} / \mathrm{w}}$ ) and homozygote (PPAR $\gamma^{\mathrm{fl} / \mathrm{fl}}$ ) mice and its absence in wild-type mice; (B and C) qPCR and western blotting analysis of isolated chondrocytes confirmed absence of PPAR $\gamma$ expression in PPAR $\gamma^{\text {fl/fl }} C r e$ mice treated with doxycycline compared with PPAR $\gamma^{\text {fl/fl }}$ Cre mice treated with saline. $\left(n=5,{ }^{*} p<0.05\right)$; (D) immunohistochemical staining for PPAR confirmed the absence of PPAR $\gamma$ expression in the articular cartilage of PPAR $\gamma^{\text {fl/fl }}$ Cre mice treated with doxycycline compared with PPAR $\gamma^{\mathrm{fl} / \mathrm{fl}} \mathrm{Cre}$ mice treated with saline $(n=4$, magnification: $\times 40)$; (E) histological analysis using Safranin O/fast green staining of 5 and 10 weeks post-OA surgery knee joint sections demonstrate that PPAR $\gamma$ KO mice exhibit accelerated osteoarthritis (OA) phenotype associated with greater cartilage degradation and loss of safranin 0 staining compared with control mice (magnification: $\times 6.2$ and $\times 25$ ); (F) Osteoarthritis Research Society International (OARSI) scoring of medial tibial plateau and medial femoral condyle showed a significant increase $\left({ }^{*} p<0.05\right)$ in the OARSI scores in both control OA and PPAR $\gamma$ KO OA mice (5 weeks and 10 weeks post-OA surgery) compared with non-surgery and sham surgery control and PPAR $\gamma$ KO mice, respectively. A significant increase $(+p<0.05)$ in the OARSI scores was observed in both 5 and 10 weeks post-OA surgery PPAR $\gamma$ KO mice compared with 5 and 10 weeks post-OA surgery control mice $(n=6) ;(G)$ quantification of articular chondrocyte cellularity revealed significant $\left({ }^{*} p<0.05\right)$ loss of chondrocyte cellularity in both control OA and PPAR $\gamma$ KO OA mice (10 weeks post-OA surgery) compared with non-surgery and sham surgery control and PPAR $\gamma$ KO mice, respectively. PPAR $\gamma$ KO mice at 10 weeks post-OA surgery exhibited significantly $(+p<0.05)$ greater loss of chondrocyte cellularity compared with control mice at 10 weeks post-OA surgery. $(n=4)$. 

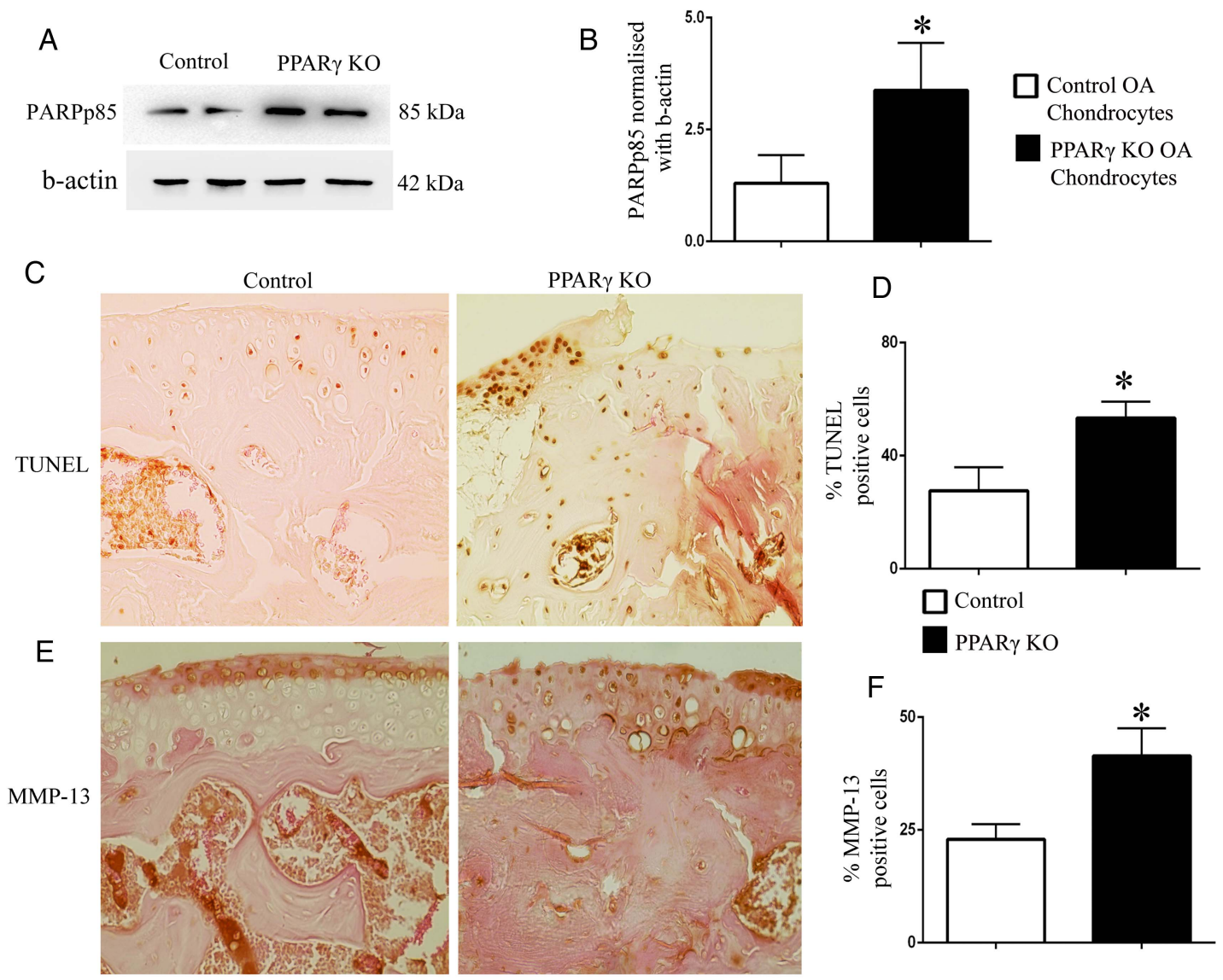

10 weeks post OA Surgery

G
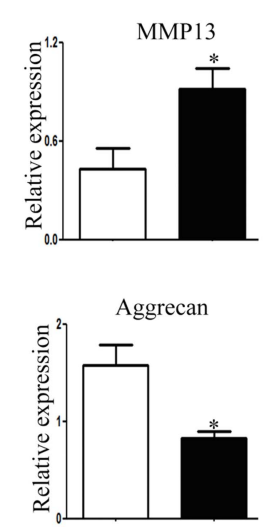
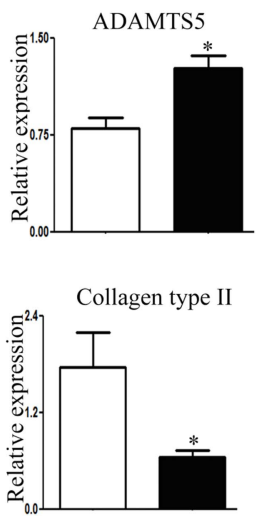
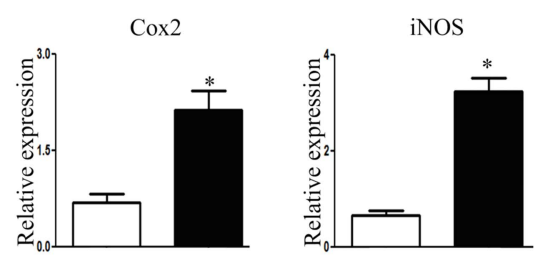

Figure 2 Peroxisome proliferator-activated receptor gamma (PPAR $\gamma$ ) knockout osteoarthritis (KO OA) mice exhibit enhanced cell death, increased expression of catabolic/inflammatory markers and decreased expression of anabolic markers: (A and B) western blotting analysis on isolated chondrocytes showed a significant increase in poly (ADP-ribose) polymerase p85 expression in PPAR $\gamma$ KO OA mice chondrocytes compared with control OA mice chondrocytes at 5 weeks post-surgery $(n=4 ; p<0.05)$; (C-F) TUNEL staining and MMP-13 immunohistochemical analysis showed a significant increase in the percentage (\%) of TUNEL and MMP-13 positive cells in PPAR $\gamma$ KO OA mice compared with control OA mice at 10 weeks post-OA surgery $(n=4$, magnification: $\times 40) ;(G)$ qPCR analysis showed a significant increase in the gene expression of MMP-13, ADAMTS-5, iNOS, and COX-2, and a significant decrease in the expression of collagen type II and aggrecan in PPAR $\gamma$ KO OA mice chondrocytes compared with control OA mice chondrocytes at 5 weeks post-OA surgery $\left(n=4,{ }^{*} p<0.05\right)$.

subsequent suppression of autophagy genes may contribute to decreased chondroprotection and cartilage degeneration. ${ }^{6}$ Further, treatment with rapamycin has been shown to reduce the severity of experimental OA. ${ }^{10}$

In the present study, we observed that PPAR $\gamma$ KO mice subjected to OA surgery exhibit accelerated chondrocyte cell death and enhanced catabolic activity. We therefore determined the effect of PPAR $\gamma$ deficiency on the expression of mTOR and autophagy markers in articular chondrocytes isolated from non- surgery and 5 weeks post-OA surgery control and PPAR $\gamma$ KO mice. As expected, ${ }^{17}$ our results first showed that PPAR $\gamma$ expression is significantly reduced in control OA surgery chondrocytes compared with control non-surgery chondrocytes (figure 3A, B). PPAR $\gamma$ expression was not detected in the PPAR $\gamma$ KO chondrocytes. The assessment of mTOR expression showed opposite expression profile compared with PPAR $\gamma$ expression profile. Low levels of mTOR expression were observed in control non-surgery chondrocytes, but were significantly 
elevated in control OA chondrocytes as expected. ${ }^{6}$ Interestingly, our results revealed that $\operatorname{PPAR} \gamma \mathrm{KO}$ chondrocytes exhibited significantly enhanced expression of mTOR in both non-surgery and OA conditions compared with chondrocytes from nonsurgery control mice and OA surgery control mice. Since mTOR negatively regulates autophagy, we further determined the expression of LC3B, an autophagosome marker for monitoring autophagy. The expression of LC3B II was significantly reduced in control OA chondrocytes compared with control non-surgery chondrocytes. Our results also revealed that PPAR $\gamma$ $\mathrm{KO}$ chondrocytes exhibited a significant decrease in LC3B II expression in both non-surgery and OA conditions compared with control chondrocytes from non-surgery mice and OA surgery mice, respectively, thus exhibiting an opposite expression profile observed for mTOR. It was interesting to notice that despite significant differences in the levels of mTOR and LC3B II expression under basal conditions (non-surgery) in PPAR $\gamma$ KO mice chondrocytes compared with control chondrocytes, we did not observe any significant differences in the articular cartilage cellularity at baseline in vivo.
qPCR analysis also confirmed a significant increase in mTOR expression and significant reduction in the expression of LC3B and other key autophagy genes including unc-51 like autophagy activating kinase 1 (ULK1) (most upstream autophagy inducer), ${ }^{23}$ autophagy gene 5 (ATG5) (an autophagy regulator), ${ }^{24}$ and BCL2/adenovirus E1B $19 \mathrm{kDa}$ protein-interacting protein 3 (BNIP3) (an interactor of LC3 in autophagy) ${ }^{25}$ in PPAR $\gamma$ KO OA chondrocytes compared with chondrocytes extracted from control OA mice (figure 3C, D).

\section{PPAR $\gamma$ regulates mTOR/autophagy signalling pathway and controls the balance between catabolic/anabolic factors in vitro}

Since PPAR $\gamma$ deficiency in the chondrocytes resulted in the aberrant expression of catabolic, anabolic and inflammatory markers associated with the dysregulated expression of mTOR and autophagy markers, we hypothesised that PPAR $\gamma$ is involved in the regulation of mTOR/autophagy pathway and may, in part, be responsible for maintaining the balance between catabolic and anabolic processes in the articular cartilage. To test this hypothesis, we transfected PPAR $\gamma$-deficient OA chondrocytes
Figure 3 Aberrant expression of mammalian target for rapamycin (mTOR) and autophagy markers in peroxisome proliferator-activated receptor gamma (PPAR $\gamma$ )-deficient chondrocytes: (A and B) PPAR $\gamma$ expression was significantly $\left({ }^{*} \mathrm{p}<0.05\right)$ reduced in chondrocytes extracted from 5-week post osteoarthritis (OA) surgery control mice compared with non-surgery control mice. PPAR $\gamma$ expression was not detected (ND) in both PPAR $\gamma$ knockout (KO) non-surgery and PPAR $\gamma$ KO OA surgery chondrocytes. A significant $\left({ }^{*} p<0.05\right)$ increase in $\mathrm{mTOR}$ protein expression and significant decrease in LC3B II expression was observed in control $\mathrm{OA}$ chondrocytes compared with control non-surgery chondrocytes as well as PPAR $\gamma$ KO OA chondrocytes compared with PPAR $\gamma$ KO non-surgery chondrocytes. A significant $(+p<0.05)$ increase in $\mathrm{mTOR}$ protein expression and decrease in LC3B II expression was observed in both PPAR $\gamma$ KO non-surgery and PPAR $\gamma$ KO OA surgery chondrocytes compared with control non-surgery and control $O A$ chondrocytes, respectively $(n=4)$; (C and D) qPCR analysis showed a significant increase in the messenger RNA (mRNA) expression of mTOR and a significant decrease in the mRNA expression of LC3B, ULK1, ATG5 and BNIP3 in PPAR $\gamma$ KO OA mice chondrocytes compared with control OA mice chondrocytes $\left(n=4,{ }^{*} p<0.05\right)$.
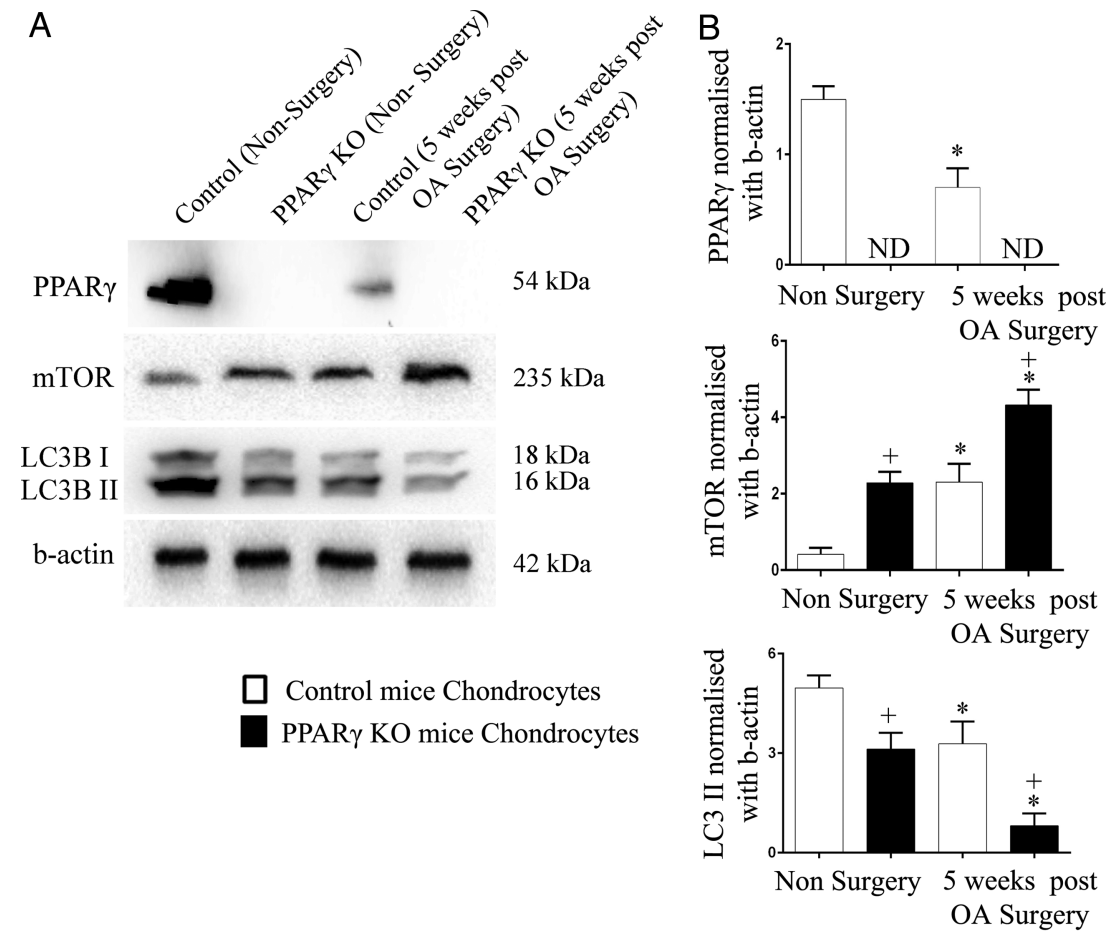

C
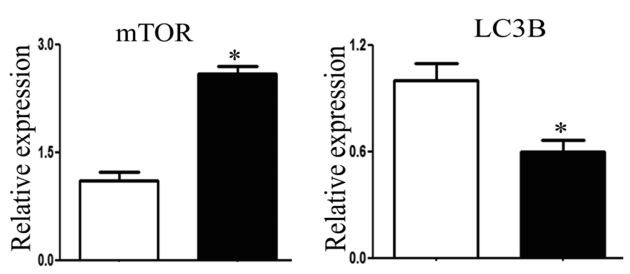

D
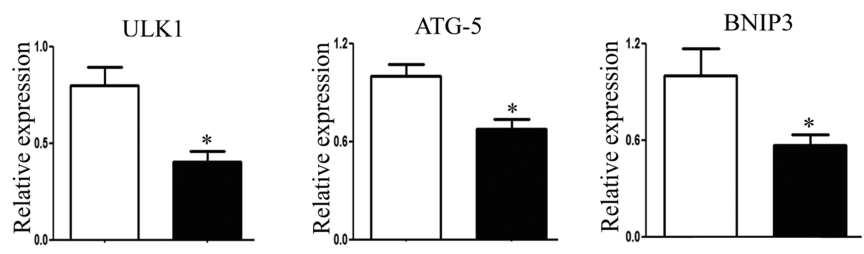

Control OA Chondrocytes

PPAR $\gamma$ KO OA Chondrocytes 
with PPAR $\gamma$ expression vector to determine if restoration of PPAR $\gamma$ expression can rescue the phenotype of PPAR $\gamma$ KO OA cells. We observed that the restoration of PPAR $\gamma$ expression in $\mathrm{KO}$ cells by PPAR $\gamma$ expression vector (figure 4A) was able to downregulate the protein and mRNA expression of mTOR (figure 4A, B), enhance the LC3B II protein expression and LC3B mRNA expression and downregulate protein and mRNA expression of MMP-13 (figure 4C, D). qPCR analysis further showed that the restoration of PPAR $\gamma$ expression in $\mathrm{KO}$ cells was able to rescue and upregulate the expression of other autophagy genes (ULK-1, ATG5 and BNIP3) and anabolic factors (collagen type II and aggrecan), as well as downregulate the expression catabolic (ADAMTS-5; a disintegrin and metalloprotease with thrombospondin motifs) and inflammatory markers (iNOS and COX-2) (figure 4E-G).

\section{Cartilage-specific PPAR $\gamma$-mTOR double KO mice exhibit protection from $0 A$}

Our results suggest that PPAR $\gamma$ deficiency in part could be responsible for increased mTOR signalling, the inhibition of critical autophagy markers, ultimately resulting in increased catabolic/inflammatory activity (and reduced anabolic activity) within the articular cartilage leading to severe/accelerated OA. To test this in vivo, we generated inducible cartilage-specific PPAR $\gamma$-mTOR double KO mice (figure $5 \mathrm{~A}-\mathrm{C}$ ). These mice were subjected to DMM surgery. Histological analysis (using OARSI scoring) in 10 weeks post-OA surgery demonstrated that PPAR $\gamma$-mTOR double KO mice were significantly protected from DMM-induced OA associated with the significant protection from cartilage destruction, proteoglycan loss and loss of chondrocytes in both medial tibial plateau and medial femoral condyle compared with control mice (figure 5D, E). The quantification of articular chondrocyte cellularity (figure 5F) and TUNEL staining (figure 5G) further confirmed a significant reduction in chondrocyte cell death in double $\mathrm{KO}$ mice compared with control mice at 10 weeks post-OA surgery. Furthermore, we also observed a significant reduction in the percentage of MMP-13-positive cells (figure $5 \mathrm{H}$ ), and enhanced LC3B II expression in double KO OA chondrocytes compared with control OA chondrocytes (figure 5I).

\section{DISCUSSION}

Autophagy is a cellular homeostatic process involving the turnover of organelles and proteins by lysosome-dependent
Figure 4 Peroxisome proliferator-activated receptor gamma (PPAR $\gamma$ ) expression vector rescues the aberrant expression of catabolic, anabolic and inflammatory markers, and the dysregulated expression of mammalian target for rapamycin (mTOR)/autophagy markers in PPAR knockout osteoarthritis (KO OA) chondrocytes: PPAR $\gamma$ KO chondrocytes (isolated at 5 weeks post-OA surgery) were cultured and transfected with PPAR $\gamma$ expression vector or empty vector. Rescue of PPAR $\gamma$ in PPAR $\gamma$ KO chondrocytes by PPAR $\gamma$ expression vector resulted in: ( $A$ and $B$ ) decrease in the protein and messenger RNA expression of mTOR $\left(n=4,{ }^{\star} p<0.05\right)$; (C) increase in LC3B II expression and decrease in MMP-13 expression $(n=4)$, (D) increase in the mRNA expression of LC3B and decrease in the mRNA expression of MMP-13; (E) increase in mRNA expression of ULK1, ATG5 and BNIP3; (F) increase in the expression of aggrecan and collagen type II and decrease in the mRNA expression of ADAMTS-5; (G) decrease in mRNA expression of COX-2 and iNOS; $(n=4$, $\left.{ }^{*} \mathrm{p}<0.05\right)$.
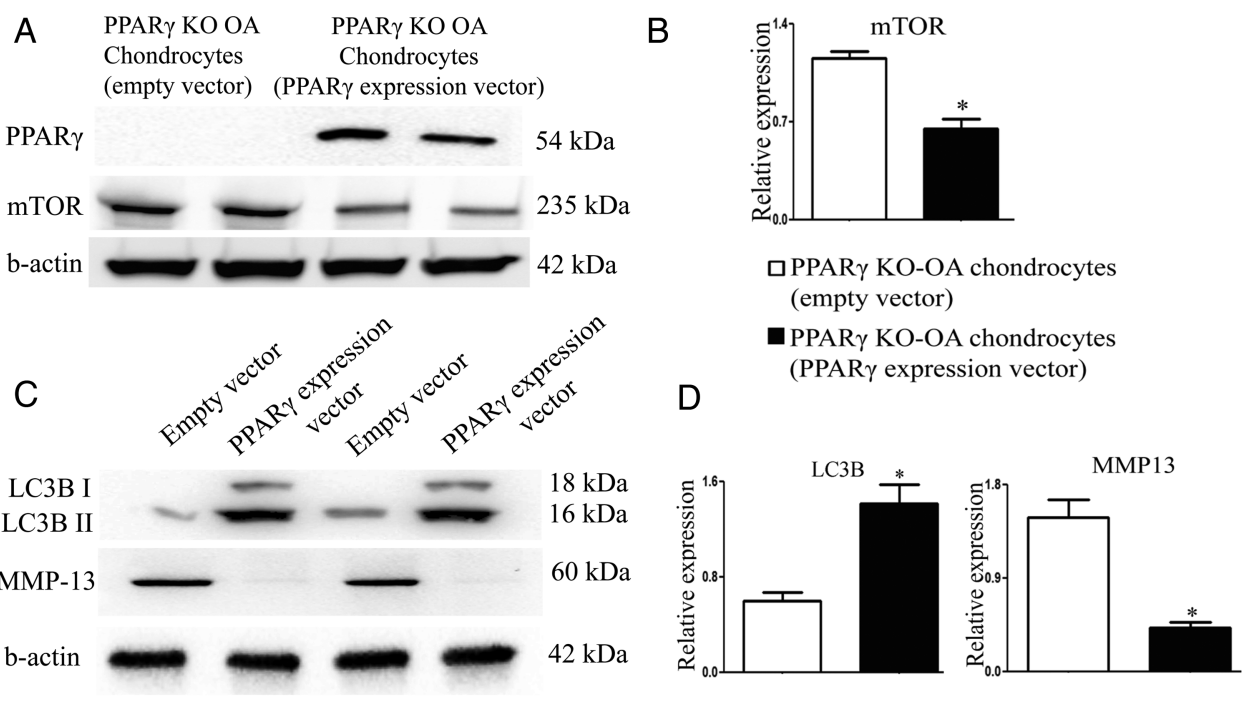

E
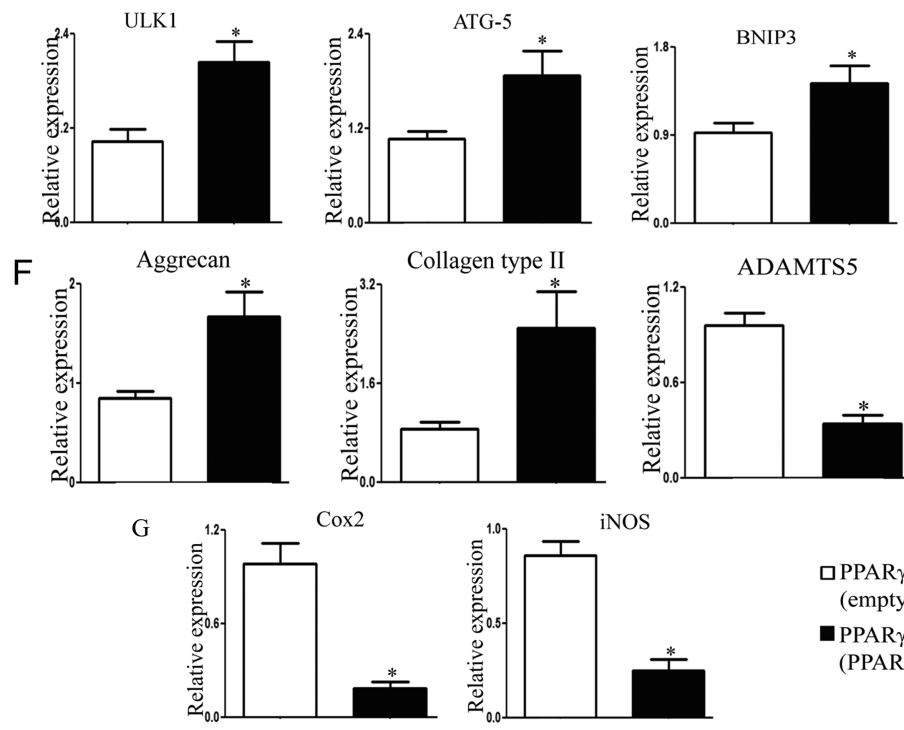

Collagen type II
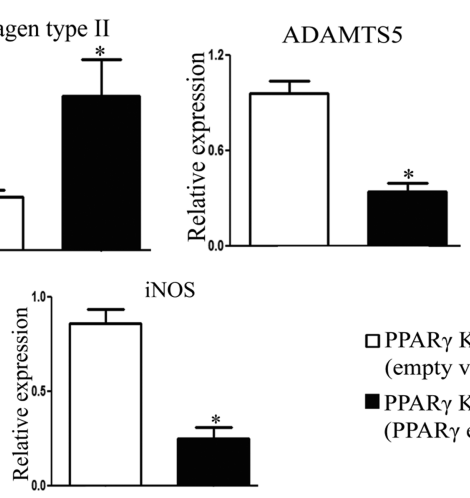

$\square$ PPAR $\gamma$ KO-OA chondrocytes (empty vector)

- PPAR $\gamma$ KO-OA chondrocytes (PPAR $\gamma$ expression vector) 

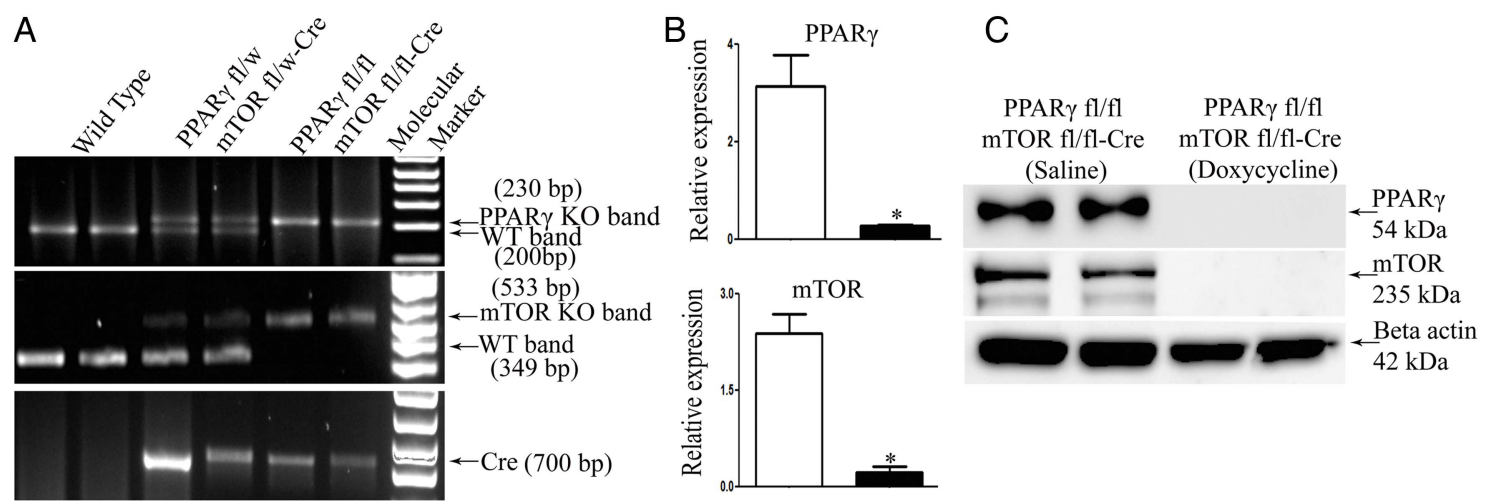

口PPAR $\gamma$ fl/fl-mTOR fl/fl-Cre (Saline)

-PPAR $\mathrm{fl} / \mathrm{fl}$-mTOR fl/fl-Cre (Doxycycline)

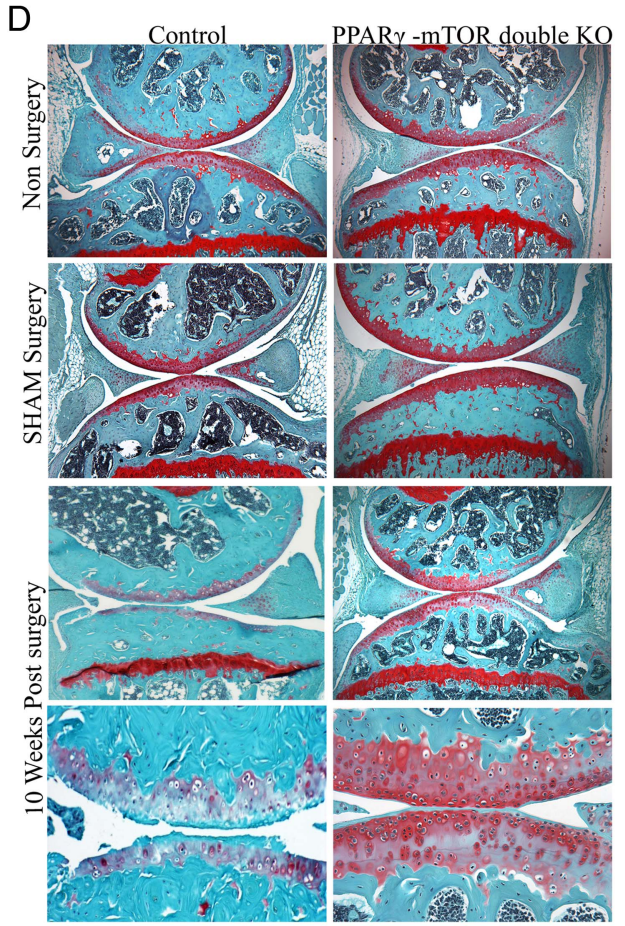

$\mathrm{F}$

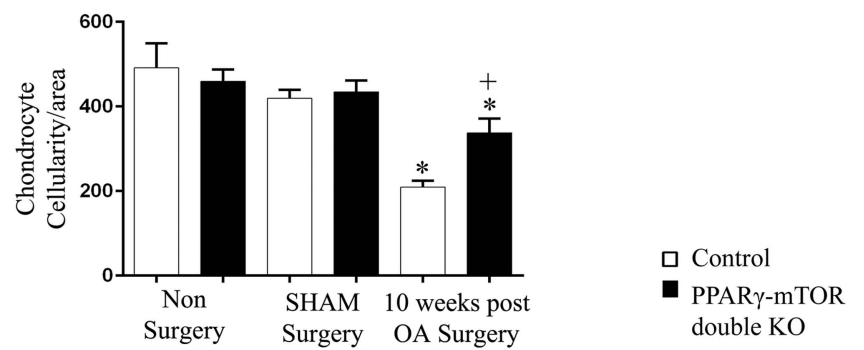

G
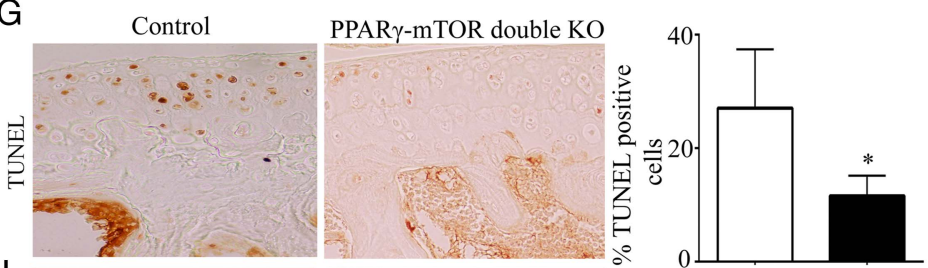

$\mathrm{H}$
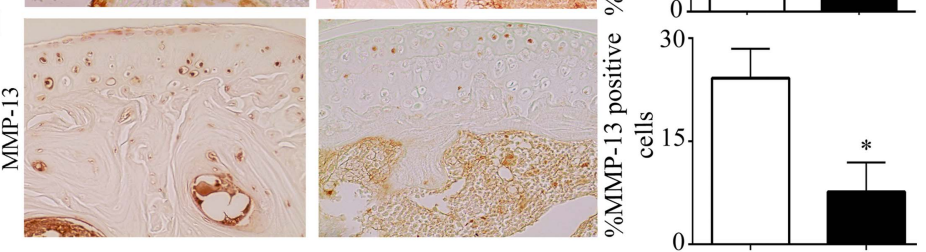

Figure 5 Inducible cartilage-specific peroxisome proliferator-activated receptor gamma (PPAR $\gamma$ )-mammalian target for rapamycin (mTOR) double knockout (KO) mouse are protected from destabilisation of medial meniscus (DMM)-induced osteoarthritis (OA): (A) genotyping confirms the presence of the Cre transgene in heterozygote (PPAR $\left.\gamma^{\mathrm{fl} / \mathrm{w}}-\mathrm{mTOR}^{\mathrm{fl} / \mathrm{w}}\right)$ and homozygote (PPAR $\left.\gamma^{\mathrm{fl} / \mathrm{fl}}-\mathrm{mTOR}^{\mathrm{fl} / \mathrm{fl}}\right)$ mice and its absence in wild-type mice; $(B$ and $C)$ qPCR and western blotting analysis of isolated chondrocytes confirmed absence of PPAR $\gamma$ and mTOR expression in PPAR $\gamma^{\mathrm{fl} / \mathrm{fl}}$-mTOR ${ }^{\mathrm{fl} / \mathrm{fl}} \mathrm{Cre}$ mice treated with doxycycline compared with PPAR $\gamma^{\mathrm{fl} / \mathrm{fl}}-\mathrm{mTOR}^{\mathrm{fl} / \mathrm{fl}} \mathrm{Cre}$ mice treated with saline $\left(\mathrm{n}=5\right.$, $\left.{ }^{*} \mathrm{p}<0.05\right)$; (D) histological analysis using safranin O/fast green staining of 10 weeks post-OA surgery knee joint sections demonstrate that in comparison with control mice, PPAR $\gamma$-mTOR double KO mice exhibit significant protection from DMM-induced OA associated with reduced cartilage degradation, proteoglycan loss and reduced loss of articular chondrocyte cellularity ( $n=5$, magnification: $\times 6.2$ and $\times 25)$; (E) Osteoarthritis Research Society International (OARSI) scoring of medial tibial plateau and medial femoral condyle showed a significant increase $\left({ }^{*} p<0.05\right)$ in the OARSI scores in both control OA and PPAR $\gamma$ KO OA mice (10 weeks post-OA surgery) compared with non-surgery and sham surgery control and PPAR $\gamma \mathrm{KO}$ mice, respectively. A significant $(+p<0.05)$ reduction in the OARSI score was observed at both medial tibial plateau and medial femoral condyle in PPAR $\gamma$-mTOR double KO mice compared with control mice at 10 weeks post-OA surgery $\left(n=5,{ }^{*} p<0.05\right)$; (F) quantification of articular chondrocyte cellularity revealed significant $\left({ }^{*} p<0.05\right)$ loss of chondrocyte cellularity in both control OA and PPAR $\gamma$ KO OA mice (10 weeks post-OA) compared with non-surgery and sham surgery control and PPAR $\gamma$ KO mice, respectively. Further, comparison between PPAR $\gamma$-mTOR double KO mice and control mice at 10 weeks post-OA surgery revealed a significant $(+p<0.05)$ protection from articular chondrocyte loss during $O A\left(n=6,{ }^{*} p<0.05\right) ;(G$ and $H)$ a significant decrease in the percentage (\%) of TUNEL and MMP-13 positive cells in PPAR $\gamma$-mTOR double KO OA mice compared with control OA mice at 10 weeks post-OA surgery $(n=4$, magnification: $\times 40) ;(I$ and $H)$ increase in light chain 3B (LC3B) II expression in PPAR $\gamma$-mTOR double KO OA mice chondrocytes compared with control $O A$ mice chondrocytes at 10 weeks post-OA surgery $\left(n=4 ;{ }^{*} p<0.05\right)$.

degradation pathway. ${ }^{26-28}$ Autophagy plays a key role in the modulation of cell death/survival, adaptive immunity, inflammation and cellular homeostasis and dysregulation in this homeostatic process has been associated with several disorders, including cardiomyopthies, neurodegeneration and abnormal skeletal development. ${ }^{29}{ }^{30} \mathrm{mTOR}$, a serine/threonine protein kinase, is a master negative regulator of autophagy, and modulates growth, proliferation, motility and 

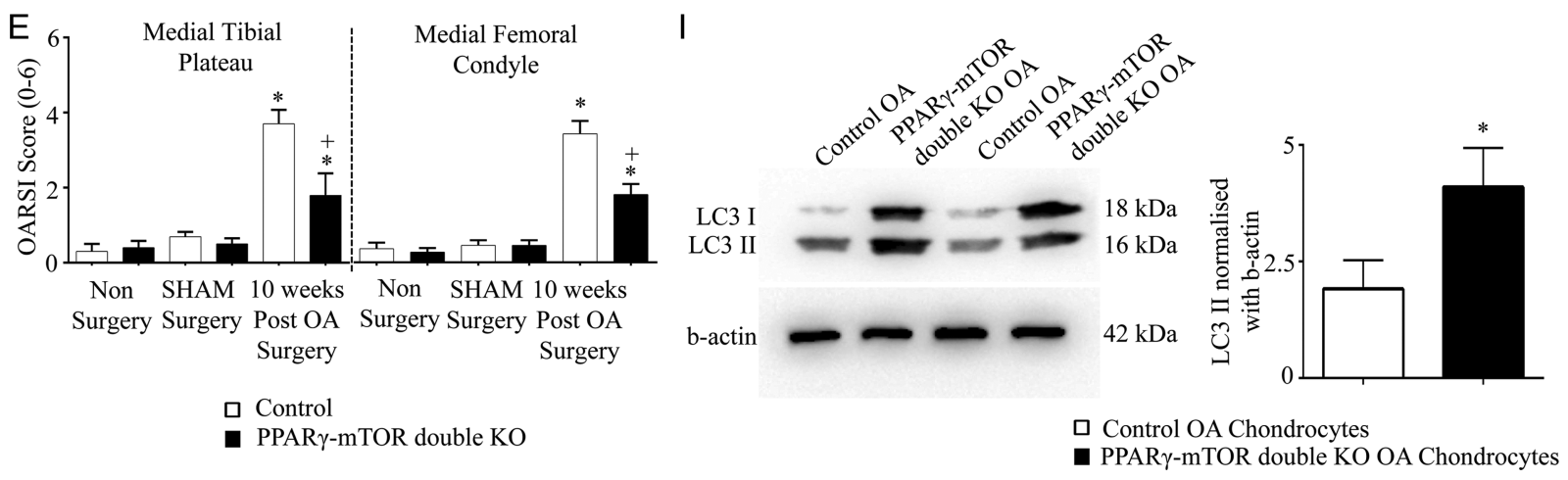

\section{Figure 5 Continued}

survival in cells. Akt has been shown to directly phosphorylate and activate mTOR as well as mTOR can negatively regulate PI3 K/Akt activity. ${ }^{31-33}$

mTOR is upregulated during OA and is associated with the suppression of autophagy signalling in the articular cartilage resulting in decreased chondroprotection, and thus promoting cartilage degeneration. ${ }^{6}$ Both the pharmacological inhibition and genetic deletion of mTOR has been shown to reduce the severity of experimental OA. ${ }^{6}{ }^{10}$ It is, however, unclear which endogenous mediators controls mTOR and autophagy signalling in the articular cartilage. Identifying endogenous mediators that control mTOR/autophagy signalling and, ultimately, the fate of articular cartilage chondrocytes will help generate new therapeutic strategies to modulate cartilage homeostasis and counteract cartilage degeneration.

PPAR $\gamma$ is a ligand-activated transcription factor known to play a key role in inflammation, fibrosis and resolution of tissue repair process. Studies suggest that the activation of this transcription factor is a therapeutic target for OA. It has been shown that agonists of PPAR $\gamma$ exhibit anti-inflammatory and anticatabolic properties in vitro and in vivo, and impart protection from OA in animal models. ${ }^{12}{ }^{16-18}$ However, studies using agonists of PPAR $\gamma$ do not elucidate the exact effects mediated by this complex gene. Indeed, some of these agonists have the ability to regulate, in vivo, various other signalling pathways independent of PPAR $\gamma$. Additionally, the in vivo role of PPAR $\gamma$ in articular cartilage homeostasis is largely unknown.

We have previously reported that germ-line cartilage-specific $\operatorname{PPAR} \gamma$ KO mice exhibit early developmental defects and exhibit accelerated spontaneous OA phenotype during adulthood. ${ }^{14}$ In the present study, we created for the first time, inducible cartilage-specific PPAR $\gamma \mathrm{KO}$ mice. Unlike germ-line cartilagespecific PPAR $\gamma$ KO mice, inducible cartilage-specific PPAR $\gamma$ KO mice did not exhibit any developmental defects and spontaneous OA phenotype.

We then subjected these mice to a DMM model of OA. Our results clearly show that the genetic deficiency of PPAR $\gamma$ in the articular cartilage results in accelerated and severe OA phenotype upon DMM surgery. Compared with control mice, cartilage-specific PPAR $\gamma$ KO mice exhibit accelerated articular cartilage degeneration associated with greater articular chondrocyte cell death, proteoglycan loss, enhanced expression of catabolic (MMP-13 and ADAMTS-5) and inflammatory mediators (COX-2 and iNOS) and reduced expression of ECM anabolic factors (aggrecan and collagen type II). Our results further show that both non-surgery (basal condition) and OA surgery PPAR $\gamma$ $\mathrm{KO}$ chondrocytes exhibit enhanced mTOR expression and decreased LC3B II expression compared with control nonsurgery and control OA mice chondrocytes.
Based on these results, we further wanted to test if the genetic deficiency of PPAR $\gamma$ and subsequent elevation in the expression of mTOR and suppression of autophagy could, in part, be responsible for increased catabolic and inflammatory activity in the articular cartilage resulting in severe OA phenotype in PPAR $\gamma$ KO mice. To test this, we transfected $\operatorname{PPAR} \gamma$-deficient OA chondrocytes with $\operatorname{PPAR} \gamma$ expression vector, and observed that the restoration of PPAR $\gamma$ expression in PPAR $\gamma$ KO cells resulted in a significant downregulation in the expression of mTOR and upregulation in the expression of LC3B II as well as elevation in the gene expression of other key autophagy genes. Additionally, the restoration of PPAR $\gamma$ expression in PPAR $\gamma \mathrm{KO}$ cells resulted in significant rescue in the expression of collagen type II and aggrecan, and downregulation in the expression of catabolic (MMP13 and ADAMTS-5) and inflammatory markers (iNOS and COX-2) in PPAR $\gamma$ KO OA chondrocytes. To further explore that mTOR and autophagy pathways are indeed responsible for severe OA phenotype observed in PPAR $\gamma \mathrm{KO}$ mice, we generated inducible cartilagespecific PPAR $\gamma$-mTOR double KO mice and subjected these mice to DMM surgery. Results showed that PPAR $\gamma$-mTOR double KO mice exhibited significant protection from DMM-induced cartilage destruction, proteoglycan loss and loss of chondrocyte-cellularity associated with significant reduction in TUNEL and MMP-13-positive cells and increase in LC3B II expression, thus reversing the accelerated $\mathrm{OA}$ phenotype observed in PPAR $\gamma \mathrm{KO}$ mice in vivo.

Our in vitro rescue studies using PPAR $\gamma$ expression vector and in vivo studies using PPAR $\gamma$-mTOR double KO mice show that PPAR $\gamma$ is involved in the regulation of mTOR/autophagy signalling in the articular cartilage. Therefore, the deficiency of PPAR $\gamma$ in the articular cartilage may, in part, be responsible for upregulation in mTOR signalling resulting in the suppression of autophagy and decreased chondroprotection and increased catabolic activity leading to accelerated severe OA. The relationship between PPAR $\gamma$ and autophagy has been previously reported in breast cancer. Zhou et al. ${ }^{34}$ showed that PPAR $\gamma$ activation by its ligands induces autophagy in breast cancer. Further, interaction between PPAR $\gamma$ and mTOR pathways during lipid uptake and adipogenesis has also been reported. ${ }^{35}{ }^{36}$ Our study, for the first time, provides a direct evidence on the role of PPAR $\gamma$ in chondroprotection, in part, by the modulation of mTOR/autophagy signalling in the articular cartilage. Since mTOR is a complex and multifactorial mediator, it is worth mentioning that the PPAR $\gamma / \mathrm{mTOR}$ signalling observed in the articular cartilage may also involve other non-autophagy pathways that require further investigation. It would also be interesting to investigate the functional consequences of interaction between PPAR $\gamma$ and two multiprotein mTOR complexes to fully elucidate the relationship 
between PPAR $\gamma$ and mTOR signalling pathway in the articular cartilage. Since the use of dual inhibitors of PI3K/Akt and mTOR has been proposed as a promising therapeutic approach in OA, ${ }^{37}$ it would be interesting to identify the exact relationship between PPAR $\gamma$ and PI3K/Akt-mTOR pathways.

\section{Author affiliations}

${ }^{1}$ Osteoarthritis Research Unit, University of Montreal Hospital Research Centre (CRCHUM), Montreal, Quebec, Canada

${ }^{2}$ Division of Genetics and Development, Toronto Western Research Institute, University Health Network (UHN), Toronto, Ontario, Canada

${ }^{3}$ Department of Clinical Sciences, Faculty of Veterinary Medicine, University of Montreal, St-Hyacinthe, Quebec, Canada

${ }^{4}$ Genetics Unit, Shriners Hospital, McGill University, Montreal, Quebec, Canada ${ }^{5}$ Pulmonary and Critical Care Unit and Center for Immunology and Inflammatory Diseases, Department of Medicine, Massachusetts General Hospital, Harvard Medical School, Massachusetts, USA

${ }^{6}$ Division of Orthopedics, Toronto Western Hospital, Toronto, Ontario, Canada

${ }^{7}$ Department of Surgery, University of Toronto, Toronto, Ontario, Canada

Acknowledgements We thank Miwand Najafe, Changshan Geng, David Hum, Francois-Cyril Jolicoeur, Frederic Pare and Francois Mineau for their technical assistance.

Contributors All authors were either involved in conception and design, or analysis and interpretation of data. Each author was involved in drafting the article and revising it critically for important intellectual content. Each author gave their final approval of the version to be published.

Funding This work is supported by MK's Canadian Institutes of Health Research Operating Grant MOP: 126016 and MOP: 106567. FV is a recipient of Graduate PhD award from the Canadian Arthritis Network (CAN)/The Arthritis Society (TAS).

\section{Competing interests None.}

Provenance and peer review Not commissioned; externally peer reviewed.

Open Access This is an Open Access article distributed in accordance with the Creative Commons Attribution Non Commercial (CC BY-NC 4.0) license, which permits others to distribute, remix, adapt, build upon this work non-commercially, and license their derivative works on different terms, provided the original work is properly cited and the use is non-commercial. See: http://creativecommons.org/ licenses/by-nc/4.0/

\section{REFERENCES}

1 Kuettner KE, Cole AA. Cartilage degeneration in different human joints. Osteoarthritis Cartilage 2005;13:93-103.

2 Blaney Davidson EN, Vitters EL, van der Kraan PM, et al. Expression of transforming growth factor-beta (TGFbeta) and the TGFbeta signalling molecule SMAD-2P in spontaneous and instability-induced osteoarthritis: role in cartilage degradation, chondrogenesis and osteophyte formation. Ann Rheum Dis 2006;65:1414-21.

3 Monemdjou R, Fahmi H, Kapoor M. Synovium in the pathophysiology of osteoarthritis. Therapy 2010;7:661-8.

4 Monemdjou R, Fahmi H, Pelletier J-P, et al. Metalloproteases in the Pathogenesis of Osteoarthritis. Int J Adv Rheumatol 2010;8:103-10.

5 Levine B, Klionsky DJ. Development by self-digestion: molecular mechanisms and biological functions of autophagy. Dev Cell 2004;6:463-77.

6 Zhang Y, Vasheghani F, Li YH, et al. Cartilage-specific deletion of mTOR upregulates autophagy and protects mice from osteoarthritis. Ann Rheum Dis 2014. Published Online First: 20 Mar 2014. doi:10.1136/annrheumdis-2013-204599

7 Sasaki H, Takayama K, Matsushita T, et al. Autophagy modulates osteoarthritisrelated gene expression in human chondrocytes. Arthritis Rheum 2012;64:1920-8.

8 Carames B, Taniguchi N, Seino D, et al. Mechanical injury suppresses autophagy regulators and pharmacologic activation of autophagy results in chondroprotection. Arthritis Rheum 2012;64:1182-92.

9 Carames B, Taniguchi N, Otsuki S, et al. Autophagy is a protective mechanism in normal cartilage, and its aging-related loss is linked with cell death and osteoarthritis. Arthritis Rheum 2010;62:791-801.

10 Carames B, Hasegawa A, Taniguchi N, et al. Autophagy activation by rapamycin reduces severity of experimental osteoarthritis. Ann Rheum Dis 2012;71:575-81.

11 Kapoor M, McCann M, Liu S, et al. Loss of peroxisome proliferator-activated receptor gamma in mouse fibroblasts results in increased susceptibility to bleomycin-induced skin fibrosis. Arthritis Rheum 2009;60:2822-9.
12 Kapoor M, Kojima F, Qian M, et al. Microsomal prostaglandin E synthase-1 deficiency is associated with elevated peroxisome proliferator activated receptor gamma: regulation by prostaglandin E2 via the PI3 kinase and AKT pathway. I Biol Chem 2007;282:5356-66.

13 Monemdjou R, Vasheghani F, Fahmi H, et al. Association of cartilage-specific deletion of peroxisome proliferator-activated receptor gamma with abnormal endochondral ossification and impaired cartilage growth and development in a murine model. Arthritis Rheum 2012:64:1551-61.

14 Vasheghani F, Monemdjou R, Fahmi $\mathrm{H}$, et al. Adult cartilage-specific peroxisome proliferator-activated receptor gamma knockout mice exhibit the spontaneous osteoarthritis phenotype. Am J Pathol 2013;182:1099-106.

15 Kapoor M, Kojima F, Qian M, et al. Microsomal prostaglandin E synthase-1 deficiency is associated with elevated peroxisome proliferator-activated receptor gamma: regulation by prostaglandin E2 via the phosphatidylinositol 3-kinase and Akt pathway. J Biol Chem 2007;282:5356-66.

16 Boileau C, Martel-Pelletier J, Fahmi H, et al. The peroxisome proliferator-activated receptor gamma agonist pioglitazone reduces the development of cartilage lesions in an experimental dog model of osteoarthritis: in vivo protective effects mediated through the inhibition of key signaling and catabolic pathways. Arthritis Rheum 2007; 56:2288-98.

17 Afif $H$, Benderdour M, Mfuna-Endam L, et al. Peroxisome proliferator-activated receptor gamma1 expression is diminished in human osteoarthritic cartilage and is downregulated by interleukin-1 beta in articular chondrocytes. Arthritis Res Ther 2007;9:R31.

18 Kobayashi T, Notoya K, Naito T, et al. Pioglitazone, a peroxisome proliferator-activated receptor gamma agonist, reduces the progression of experimental osteoarthritis in guinea pigs. Arthritis Rheum 2005;52:479-87.

19 Barak Y, Nelson MC, Ong ES, et al. PPAR gamma is required for placental, cardiac, and adipose tissue development. Molecular Cell 1999;4:585-95.

20 Grover J, Roughley PJ. Generation of a transgenic mouse in which Cre recombinase is expressed under control of the type II collagen promoter and doxycycline administration. Matrix Biol 2006;25:158-65.

21 Valverde-Franco G, Pelletier JP, Fahmi H, et al. In vivo bone-specific EphB4 overexpression in mice protects both subchondral bone and cartilage during osteoarthritis. Arthritis Rheum 2012;64:3614-25.

22 Glasson SS, Chambers MG, Van Den Berg WB, et al. The OARSI histopathology initiative-recommendations for histological assessments of osteoarthritis in the mouse. Osteoarthritis Cartilage 2010;18(Suppl 3):S17-23.

23 Inoki K, Kim J, Guan KL. AMPK and mTOR in cellular energy homeostasis and drug targets. Annu Rev Pharmacol Toxicol 2012;52:381-400.

24 Kuma A, Hatano $M$, Matsui $M$, et al. The role of autophagy during the early neonatal starvation period. Nature 2004;432:1032-6.

25 Hanna RA, Quinsay MN, Orogo AM, et al. Microtubule-associated protein 1 light chain 3 (LC3) interacts with Bnip3 protein to selectively remove endoplasmic reticulum and mitochondria via autophagy. J Biol Chem 2012;287:19094-104.

26 Levine B, Kroemer G. Autophagy in the pathogenesis of disease. Cell 2008;132:27-42.

27 Eskelinen EL, Saftig P. Autophagy: a lysosomal degradation pathway with a central role in health and disease. Biochim Biophys Acta 2009;1793:664-73.

28 Mizushima N, Levine B, Cuervo AM, et al. Autophagy fights disease through cellular self-digestion. Nature 2008;451:1069-75.

29 Hara T, Nakamura K, Matsui M, et al. Suppression of basal autophagy in neural cells causes neurodegenerative disease in mice. Nature 2006;441:885-9.

30 Komatsu M, Waguri S, Ueno T, et al. Impairment of starvation-induced and constitutive autophagy in Atg7-deficient mice. J Cell Biol 2005; 169:425-34.

31 LoPiccolo J, Blumenthal GM, Bernstein WB, et al. Targeting the PI3K/Akt/mTOR pathway: effective combinations and clinical considerations. Drug Resist Updat 2008; 11:32-50.

32 Harrington LS, Findlay GM, Lamb RF. Restraining PI3K: mTOR signalling goes back to the membrane. Trends Biochem Sci 2005;30:35-42.

33 Sarbassov DD, Guertin DA, Ali SM, et al. Phosphorylation and regulation of Akt/ PKB by the rictor-mTOR complex. Science 2005;307:1098-101.

34 Zhou J, Zhang W, Liang B, et al. PPARgamma activation induces autophagy in breast cancer cells. Int I Biochem Cell Biol 2009;41:2334-42.

35 Blanchard PG, Festuccia WT, Houde VP, et al. Major involvement of mTOR in the PPARgamma-induced stimulation of adipose tissue lipid uptake and fat accretion. J Lipid Res 2012;53:1117-25.

$36 \mathrm{Kim} \mathrm{JE}$, Chen J. regulation of peroxisome proliferator-activated receptor-gamma activity by mammalian target of rapamycin and amino acids in adipogenesis. Diabetes 2004;53:2748-56.

37 Chen J, Crawford R, Xiao Y. Vertical inhibition of the PI3K/Akt/mTOR pathway for the treatment of osteoarthritis. J Cell Biochem 2013;114:245-9. 